\title{
Changes in passive ankle stiffness and its effects on gait function in people with chronic stroke
}

\author{
Anindo Roy, PhD $;^{1-2 *}$ Larry W. Forrester, PhD $;^{1-3}$ Richard F. Macko, MD $\dot{;}^{1-4}$ Hermano I. Krebs, PhD ${ }^{1,5}$ \\ ${ }^{1}$ Department of Neurology, University of Maryland School of Medicine, Baltimore, MD; ${ }^{2}$ Maryland Exercise and \\ Robotics Center of Excellence, Baltimore Department of Veterans Affairs Medical Center (VAMC), Baltimore, MD; \\ ${ }^{3}$ Department of Physical Therapy and Rehabilitation Science, University of Maryland School of Medicine, Baltimore, \\ $M D ;{ }^{4}$ Geriatric Research Education and Clinical Center, Baltimore VAMC, Baltimore, MD; 5 Department of Mechani- \\ cal Engineering, Massachusetts Institute of Technology, Cambridge, MA
}

\begin{abstract}
Mechanical impedance of the ankle is known to influence key aspects of ankle function. We investigated the effects of robot-assisted ankle training in people with chronic stroke on the paretic ankle's passive stiffness and its relationship to overground gait function. Over $6 \mathrm{wk}$, eight participants with residual hemiparetic deficits engaged in a visuomotor task while seated that required dorsiflexion (DF) or plantar flexion (PF) of their paretic ankle with an ankle robot ("anklebot") assisting as needed. Passive ankle stiffness (PAS) was measured in both the trained sagittal and untrained frontal planes. After $6 \mathrm{wk}$, the PAS decreased in both DF and PF and reverted into the variability of age-matched controls in DF. Changes in PF PAS correlated strongly with gains in paretic step lengths (Spearman rho $=-0.88, p=0.03$ ) and paretic stride lengths (Spearman rho $=-0.82, p=0.05$ ) during independent floor walking. Moreover, baseline PF PAS were correlated with gains in paretic step lengths (Spearman rho $=0.94, p=0.01$ ), paretic stride lengths (Spearman rho $=0.83, p=0.05$ ), and singlesupport stance duration (Spearman rho $=0.94, p=0.01$ ); and baseline eversion PAS were correlated with gains in cadence (Spearman rho $=-0.88, p=0.03$ ). These findings suggest that ankle robot-assisted, visuomotor-based, isolated ankle training has a positive effect on paretic ankle PAS that strongly influences key measures of gait function.
\end{abstract}

Key words: ankle impairment, ankle robot, ankle stiffness, chronic stroke, foot drop, hemiparetic gait, lower limb, motor control, rehabilitation, robotic therapy.

\section{INTRODUCTION}

With nearly 800,000 Americans experiencing a stroke each year [1], stroke rehabilitation remains a challenge. In the lower limb, a common condition that occurs following a stroke is weakness in the dorsiflexor muscles that lift the foot during walking, commonly referred to as "drop foot." The two major complications of drop foot-slapping of the foot after heel strike (foot slap) and dragging of the toe during swing (toe drag) - present a major challenge to

\footnotetext{
Abbreviations: $\mathrm{A} / \mathrm{P}=$ anterior-posterior, $\mathrm{AROM}=$ active range of motion, $b \mathrm{EMG}=$ background electromyography, $\mathrm{DF}=$ dorsiflexion, DOF $=$ degree of freedom, DST $=$ double-support stance, $\mathrm{EMG}=$ electromyography, $\mathrm{EV}=$ eversion, $\mathrm{GAS}=$ gastrocnemius, GRECC $=$ Geriatric Research Education and Clinical Center, $\mathrm{HC}=$ home, $\mathrm{INV}=$ inversion, $\mathrm{LC}=$ limited community, $\mathrm{MIT}=$ Massachusetts Institute of Technology, PAS = passive ankle stiffness, $\mathrm{PF}=$ plantar flexion, $\mathrm{PMS}=$ prolonged muscle stretch, $\mathrm{PROM}=$ passive range of motion, $\mathrm{ROM}=$ range of motion, $\mathrm{SD}=$ standard deviation, SPCA = summed physiological cross-sectional area, SST $=$ single-support stance, $\mathrm{STP}=$ step, $\mathrm{STR}=$ stride, $\mathrm{TA}=$ tibialis anterior, $\mathrm{VA}=$ Department of Veterans Affairs, VAMC $=$ Department of Veterans Affairs Medical Center. *Address all correspondence to Anindo Roy, PhD; VA Maryland Healthcare System, Baltimore VAMC Annex, 209 W Fayette St, Ste 214, Baltimore, MD 21210; 410-200-0894; fax: 410-605-7913. Email: ARoy@som.umaryland.edu http://dx.doi.org/10.1682/JRRD.2011.10.0206
} 
efficient gait since clearing the ground during the swing phase and maintaining ankle stability during the stance phase are essential for efficient gait. The ankle plays a fundamental role in locomotion in several ways. First, it contributes to the maintenance of stable upright posture in the frontal and sagittal planes during gait. Second, the ankle contributes to shock absorption during locomotion by attenuating the impact force at floor contact [2]. Third, the ankle muscles are the primary contributors to overground gait - the soleus is the propulsion prime-mover, the gastrocnemius (GAS) is the posture prime-mover, and the tibialis anterior (TA) is critical for toe-off [3]. All these aspects of ankle function may be characterized by its active and passive mechanical impedance, i.e., stiffness plus damping and any other dynamic factors. Studies have shown that humans adjust leg stiffness to accommodate surface changes [4-5] and changes in gait speed [6] primarily by modulating ankle stiffness [5-6]. Adequate ankle impedance is also needed to control body momentum (forward and downward vector components of the body center of mass) during gait [7].

The mechanical impedance of a joint is a function of both passive (e.g., mechanical stiffness of ligaments, tendons, and connective tissue) and active (e.g., muscle activation, contraction mediated by stretch reflex) mechanisms. In physical terms, passive stiffness is the change in tension per unit change in length (massless "spring" analogy), or in the context of muscle mechanics, it may be defined as the resistance to elongation or shortening of a muscle when it is quiescent, thus generating passive tension. Studies suggest that the series elastic and parallel elastic elements of muscle (e.g., tendon, structural proteins within the myofibril, connective tissue around the muscle fibers, and fascicles) play a role in generating this passive tension [8]. Evidence from animals [9] as well as disabled [10] and nondisabled [10] humans suggests that the stiffness accompanies a shortening of the muscle belly through the loss of sarcomeres in series. Studies have reported that structures such as perimysium that contain collagen within the muscle tendon unit contribute to passive stiffness, mostly at end-range (long sarcomere lengths). Within the physiological range of muscle length change, passive stiffness has been attributed to protein structures within the myofibril, such as titin [11-12].

In impaired patients, hypertonus and/or reflex hyperexcitability (spasticity) often disrupt the functional use of already-weakened muscles [13]. In fact, the manifestation of increased motor neuron excitability and an increased resistance to passive movement have been observed in clinical assessments [14-18]. In addition, structural changes of muscle fibers and connective tissue may contribute to alterations in the intrinsic mechanical properties, e.g., stiffness of a joint. Our previous study [19], for instance, demonstrated that individuals with stroke have abnormal levels of passive ankle stiffness (PAS) at the paretic ankle in addition to complications such as hypertonia and spasticity [18-19].

Despite the ankle's important role in locomotion, few rehabilitation practices actually focus on training the impaired ankle. Techniques such as prolonged muscle stretch (PMS) have been shown to increase the passive range of motion (PROM), decrease the passive resistance of ankle dorsiflexors, and suppress hypertonia [20]; however, these techniques tend to be highly subjective or preferential with little or no quantitative guidelines for clinical practitioners. To our knowledge, few studies have focused on the long-term effects of repeated stretching of hemiparetic ankles [20-21] and even fewer have measured and monitored changes in ankle stiffness over the course of some intervention [21-23]. Even so, it remains unclear whether changes in sagittal or frontal plane PAS affect locomotor function.

We have deployed in the clinic an impedancecontrolled ankle robot (anklebot) [24] developed at the Massachusetts Institute of Technology (MIT) and are testing it with patients with chronic stroke at the Baltimore Department of Veterans Affairs (VA) Medical Center (VAMC). This 3-degrees of freedom (DOFs) wearable device provides actuation in two of these DOFs, namely dorsiflexion (DF)-plantar flexion (PF) and inversion (INV)-eversion (EV) [24]. In a recent study [25], we demonstrated that people with chronic stroke who used the anklebot for $6 \mathrm{wk}$ (3 times/wk) to play a video game in a seated position with their paretic ankle in DF-PF ranges had reduced paretic ankle impairments (increased active range of motion [AROM] in PF), improved paretic ankle motor control (increased mean and peak speed, smoothness, and accuracy of ankle targeting), and increased unassisted floor-walking speeds as well as improvements in key spatiotemporal gait parameters (higher cadence, paretic stride [STR] length, and longer single-support stance [SST] duration with concomitantly shorter double-support stance [DST] duration). Using procedures described previously [19], we used the anklebot to estimate PAS in both DF-PF and INV-EV ranges of motion (ROMs) over the course of training in a sample of eight subjects with chronic stroke, 
and we present additional data and analysis here as a follow-up to Roy et al. [19].

Our objective here was to evaluate the effects of visuomotor-guided, performance-based, progressive anklebot training on paretic PAS in chronic stroke and to assess the relationship between those changes and selected aspects of unassisted overground gait. In light of prior findings on passive ankle stretching [20-23] as well as our experience in upper-limb rehabilitation in stroke [26-33], we hypothesized that after 6 wk of anklebot training, the paretic PAS would change in the trained sagittal plane, i.e., DF-PF, but not in the untrained frontal plane, i.e., INV-EV. Moreover, we expected that, to be functionally meaningful, a robotic treatment protocol must emphasize a sequence and timing of sensorimotor stimuli similar to those naturally occurring during gait. Hence, we also hypothesized that changes in PAS resulting from training in the seated position would not carry over and confer improvements in functional recovery, e.g., gait.

\section{METHODS}

\section{Participants}

Eight subjects with chronic-stage stroke (6 female, 2 male) participated in this single-arm pilot study and were the same subjects we studied in a previous report [25]. Subjects were older than $21 \mathrm{yr}$ at the time of examination, had their stroke more than 6 (ischemic) or 12 (hemorrhagic) mo preceding the study, had completed all conventional physical therapy prior to enrollment, possessed adequate language and neurocognitive function to comprehend instructions, and had residual hemiparetic gait and paretic ankle deficits. All subjects underwent routine medical and cardiovascular evaluations in the Baltimore VA Geriatric Research Education and Clinical Center (GRECC) Assessment Clinic prior to study enrollment.

\section{Apparatus (Anklebot)}

MIT's anklebot was used for training as well as stiffness measurement. Its design and measurement capabilities have previously been described [24]. Briefly, the impedance-controlled anklebot (Interactive Motion Technologies; Watertown, Massachusetts) is an exoskeleton that is backdriveable, possesses intrinsically low mechanical impedance, and allows normal ROM in all three DOFs of the foot relative to the shank during walking or while seated but provides independent, active assistance or resistance in only DF-PF and INV-EV.

\section{Procedures}

\section{Training Protocol}

Training procedures are described in detail elsewhere [25]. We report only the main features here. Subjects sat in a "barber's" chair, wearing the anklebot on their paretic leg with the knee flexed at $45^{\circ}$ and the heel placed on a base to provide a pivot point, thus isolating the foot so it could move freely about the ankle (Figure 1(a)). Training was three times per week and consisted of subjects playing a video game with their paretic ankle by making alternate movements in $\mathrm{DF}$ and $\mathrm{PF}$, which moved a robotcontrolled cursor "up" or "down" on a display screen in order to pass through targets that approached across the display screen at different vertical levels. Target locations were set at \pm 80 and \pm 40 percent of AROM in each direction. Each session, during which subjects made 560 targeted ankle movements, consisted of eight blocked trials, with the first and last being "record-only" blocks consisting of 40 targets (at $0.25 \mathrm{~Hz}$ ) without any robotic assistance, while the six intermediate blocks each consisted of 80 targets $(0.44 \mathrm{~Hz})$ with robotic assistance decreased incrementally after every two blocks $(100 \mathrm{Nm} / \mathrm{rad}$ to $50 \mathrm{Nm} / \mathrm{rad}$ to $25 \mathrm{Nm} / \mathrm{rad}$ ). Note that when a target appeared in $\mathrm{DF}$ or $\mathrm{PF}$, the robot generated torques as per the target location (which determined the command voltages to the motors); however, ankle movement was uncontrolled and unactuated in the INV-EV directions (i.e., no voltages were commanded to the motors in these directions) - in other words, the ankle was free to move in the untrained frontal plane. To sustain subject motivation, the video game adopted a performance-based progression algorithm (Figure 2) that included increasing the target ROM by 10 percent in weeks 3-4 and frequency of target presentation by $0.06 \mathrm{~Hz}$ in weeks $5-6$ in the assisted trials, but only if tolerated; in this context, achieving at least 64 out of 80 targets in at least one assisted block with the new settings. Otherwise, we used the prior settings. We held the target presentations for the record-only trials constant throughout the training program.

\section{Stiffness Measurement}

The PAS measurement procedure has been previously described in detail [19]. Briefly, the anklebot stretched the paretic ankle at a constant $(5 \%$ s) velocity according to ramp up-hold-ramp down positional reference trajectory (Figure 1(b)). The rationale to stretch the ankle at $5 \%$ s (both ramp 
JRRD, Volume 50, Number 4, 2013

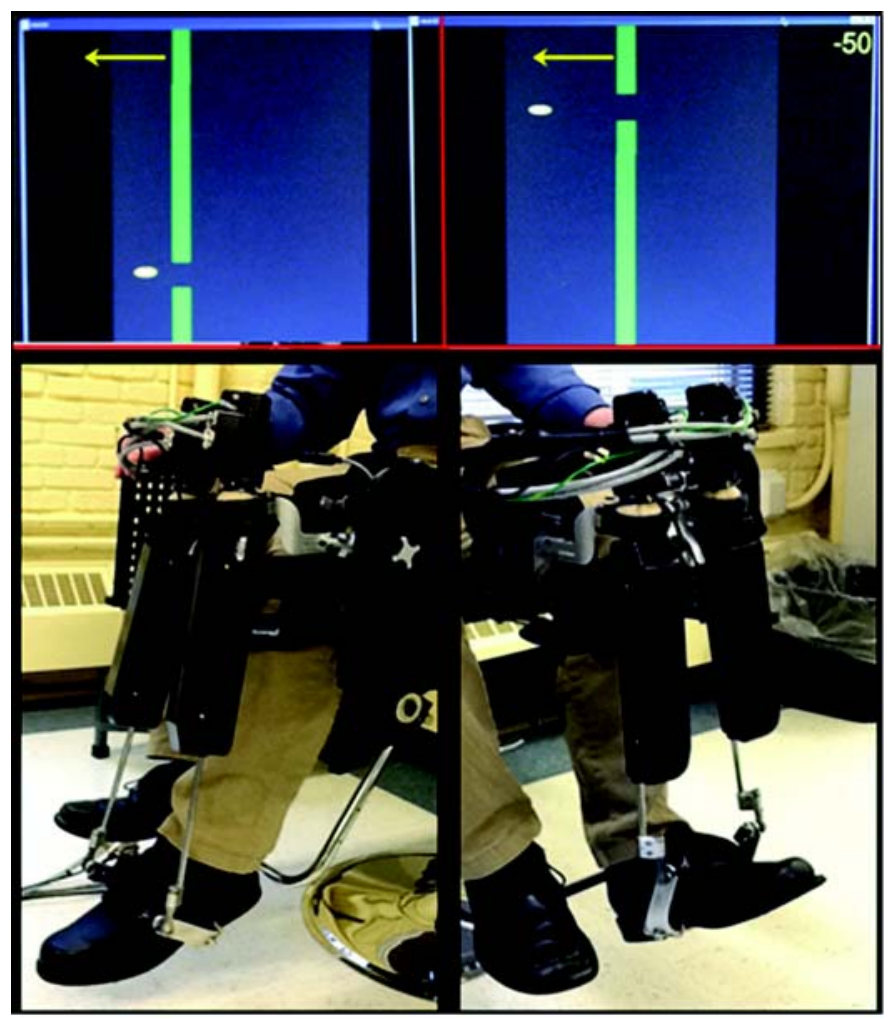

\section{Figure 1.}

Experimental setup showing subject with stroke training with Department of Veterans Affairs-Massachusetts Institute of Technology ankle robot (anklebot) in seated position while playing visually evoked, visually guided ankle targeting video game. Arrows denote motion of vertical gates that serve as targets for anklebot- and foot-controlled cursor. Subject is required to either plantar flex (left column) or dorsiflex (right column) his or her ankle from current position to move cursor toward appropriate approaching gate with anklebot assisting "as needed." Bottom panel shows close-up view of subject's foot movement in either dorsiflexion (DF) or plantar flexion (PF) while playing video game or, during stiffness assessment, when ankle is passively stretched by anklebot to measure torque-angle data used to estimate passive ankle stiffness. Knee brace (partly seen) is mounted to fixed plate that supports anklebot and restricts translational (but not rotational) knee movements, effectively isolating ankle movements in either DF-PF or inversioneversion planes.

up and ramp down) was to avoid evoking stretch reflex, as reported in other studies [15,19,34-35]. Under the relaxed condition, subjects experienced a series of perturbations during which the ankle was stretched to a commanded position, held at steady state for $1 \mathrm{~s}$, and returned to neutral. The

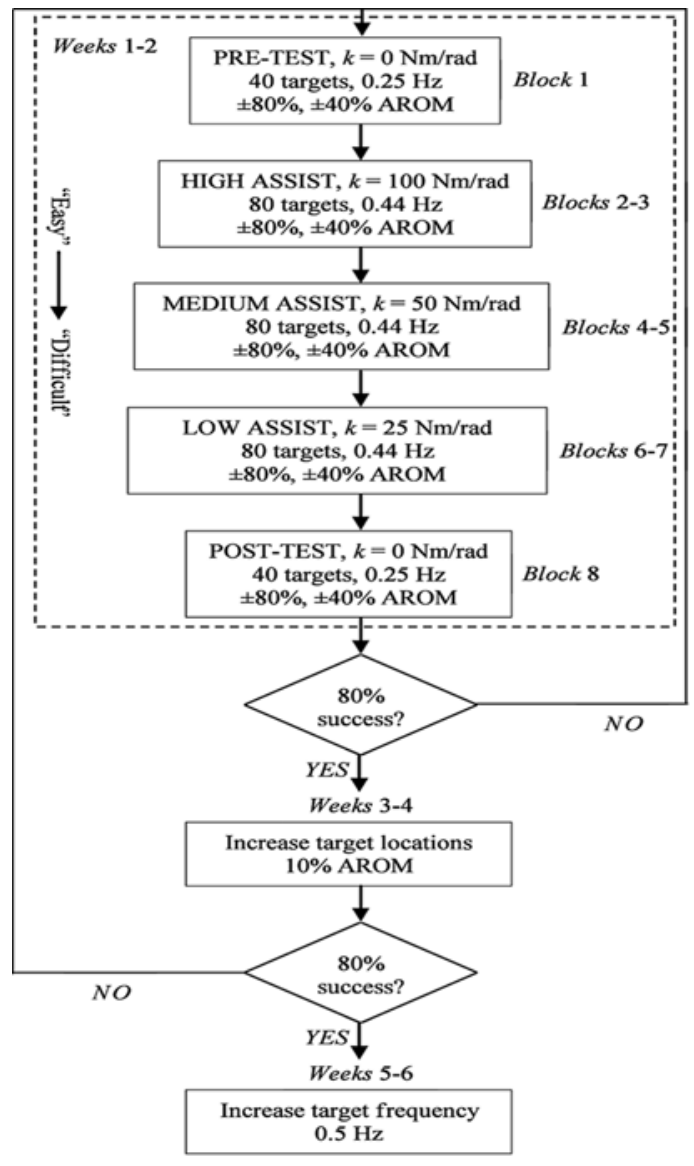

Figure 2.

Algorithm used for performance-based progressive training over 6 wk training period. Target locations in visuomotor task are set at each subject's baseline active range of motion (AROM) for both directions (dorsiflexion and plantar flexion). "Easy-todifficult" sequence in terms of progressively decreasing robotic support, determined by stiffness setting: $K(\mathrm{Nm} / \mathrm{rad})$, is same for each visit throughout training, but task difficulty in terms of vertical location of targets (challenging AROM) and speed of targets (challenging speed of ankle targeting) on screen are adjusted in weeks 3-4 and 5-6, respectively, based on prior subject performance in order to provide challenge where applicable (at least sustained $80 \%$ targeting success without robotic assistance in weeks 1 and 2) and sustain subject motivation.

range of stretch amplitudes depended on the plane and direction of movement; in the sagittal plane, displacements ranged from $20^{\circ}$ in PF to the subject's PROM in DF. In the frontal plane, stretch amplitudes ranged from $25^{\circ}$ in INV to $20^{\circ}$ in EV. Stretches were made in $5^{\circ}$ increments (e.g., neutral to $\pm 5^{\circ}$ and back to neutral, neutral to $\pm 10^{\circ}$ and back to 
neutral, and so on). Note that during stretch in one plane of movement (e.g., sagittal), the other plane of movement (e.g., frontal) was completely uncontrolled without any resistance or assistance, i.e., no movement (voltages) were commanded (see "Discussion" section for more details). Consistent with our previous study [19], we considered angles and torques in DF and EV positive and those in PF and INV negative. To ensure repeatability, subjects conducted each stretch three times at a given amplitude.

\section{Outcome Evaluation}

\section{Measures}

The primary outcome measure was PAS in the sagittal and frontal planes, evaluated at baseline, midpoint ( $3 \mathrm{wk}$ ), and termination (discharge), employing methods described elsewhere [19]. Data on paretic ankle impairment (e.g., DF-PF AROM and PROM, dorsiflexor strength, and Modified Ashworth scores), motor control, and measures of overground gait function have been previously reported [25]. Here, we report only the salient features of the stiffness measurement, assessment of gait outcomes, and computation of measures of ankle motor control.

\section{Passive Ankle Stiffness Computation}

We estimated PAS in each direction by fitting the pair-wise steady-state torque and angle data using leastsquares linear regression (Figure 3) [19]. To minimize the confounding effects of any nonlinearities in the torque-angle curves (which may yield different stiffnesses at different operating ranges), we identified "outliers" and excluded them from the data analyses. We defined outliers as those data points that corresponded to either (1) actuator saturation, i.e., when the physical "hard limit" was reached during a stretch; or (2) "observable" nonlinearity, e.g., an isometric condition (finite torque but negligible movement), occurring typically at limbs of movement where the torque-angle relationship tended toward a vertical asymptote-type behavior.

\section{Electromyography}

To confirm our assumption of zero voluntary contribution during passive stretch, we recorded surface electromyography (EMG) (patch electrode with snap connector and encapsulated preamplifiers, Cadwell Laboratories, Inc; Kennewick, Washington) from both the paretic and nonparetic primary plantar flexor (GAS) and dorsiflexor (TA) muscles [19]. We recorded EMG from ipsilat- eral (paretic) as well as contralateral (nonparetic) muscles in order to compare and establish background (quiescent muscle) activity. We sampled EMG recording at $1 \mathrm{kHz}$, commenced $5 \mathrm{~s}$ prior to the onset of each stretch, and continued until hold phase was completed. The raw EMG signals were filtered using an eighth-order, zero-lag, highpass Butterworth filter with cutoff frequency of $475 \mathrm{~Hz}$ and subsequently rectified and de-trended. We established a baseline measure of background EMG ( $b$ EMG) as the average EMG activity in an artifact-free time window of $5 \mathrm{~s}$ prior to the onset of stretch. During each stretch, we compared the mean EMG activity against $b \mathrm{EMG} \pm 1$ standard deviation (SD). Moreover, in order to identify presence of potential transient stretch reflex activity, we compared the EMG amplitude at each sample during stretch with its corresponding $b \mathrm{EMG} \pm 1 \mathrm{SD}$.

\section{Gait Assessments}

Subjects performed overground walking at selfselected comfortable speed on an $8 \mathrm{~m}$ instrumented walkway (CIR Systems; Sparta, New Jersey) with at least two STRs before the start and after the end for acceleration and deceleration [25]. Subjects walked without the use of any assistive devices. We did not include first and last steps (STPs) in the analyses to eliminate partial foot contacts at the extremes of the recording area. Spatiotemporal outcomes included mean speed (centimeters per second), paretic STR and paretic STP lengths (centimeters), cadence (steps per minute), paretic-to-nonparetic STP length, and paretic single support and double support (\%cycle). Subjects repeated all tests three times, with $1 \mathrm{~min}$ rests between them, and we used the average across the three trials for analysis. We performed gait assessments at three time points during the training program: at baseline, ${ }^{\dagger}$ at $3 \mathrm{wk}$, and at termination or discharge (6 wk).

\footnotetext{
*We calculated paretic STP length as the distance between the points of heel strike of the nonparetic and paretic foot. We calculated STR length as the distance between successive points of heel strike of the paretic leg.

${ }^{\dagger}$ For baseline and termination (discharge), we conducted gait assessments $1 \mathrm{wk}$ before and after the first and last training visit, respectively. At 3 wk, we conducted the gait assessment on the same day as training but after a break ( $\sim 30 \mathrm{~min}$ to $1 \mathrm{~h}$ ) following the training session in order to maximize or "wash out" any potentially confounding effects resulting from fatigue.
} 

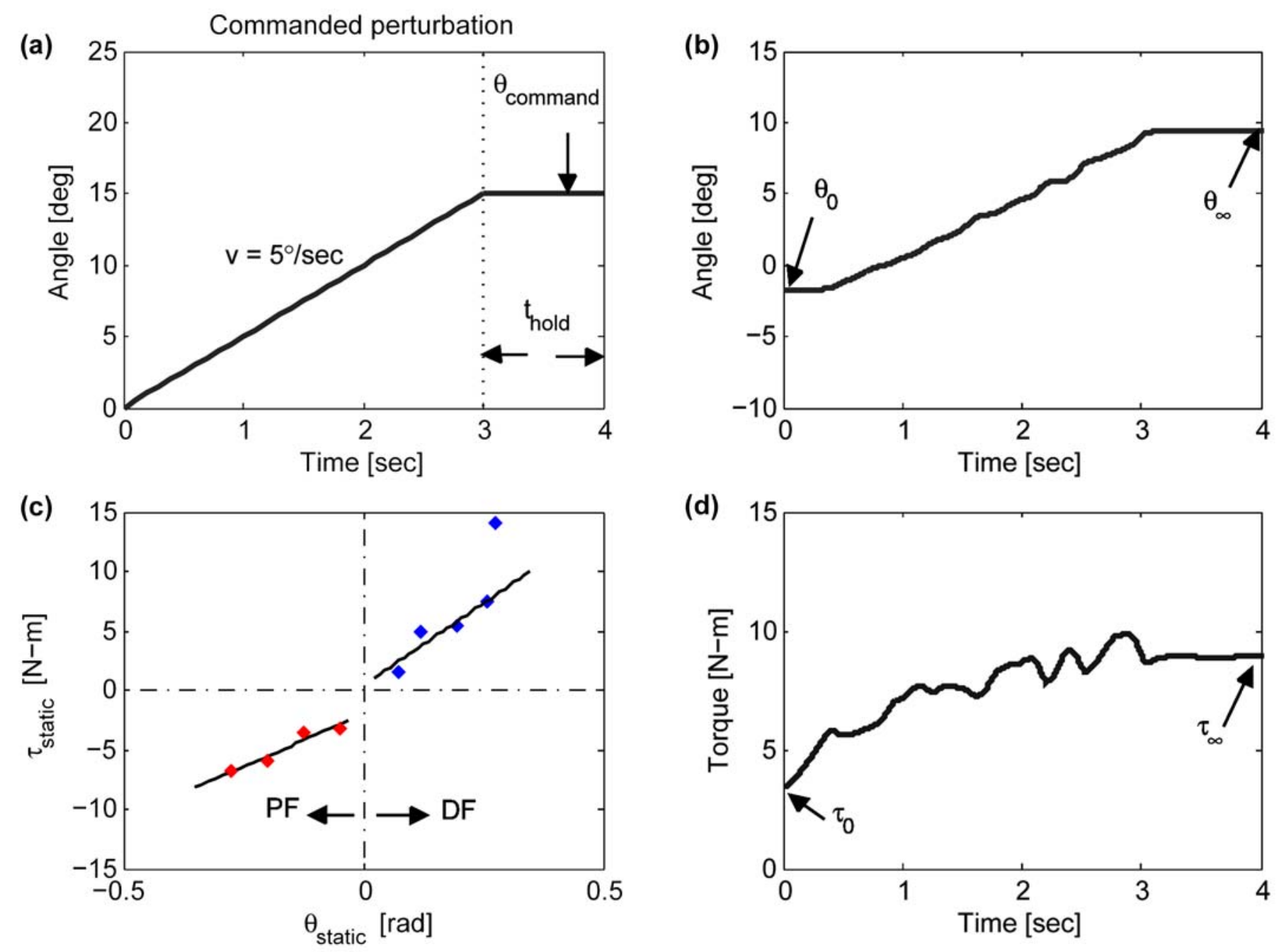

Figure 3.

Measurement of passive ankle stiffness using anklebot. (Reprinted with permission from Roy A, Krebs HI, Bever CT, Forrester LW, Macko RF, Hogan N. Measurement of passive ankle stiffness in subjects with chronic hemiparesis using a novel ankle robot. J Neurophysiol. 2011;105:2132-49.) (a) Commanded ramp-and-hold displacement perturbation $\left(\theta_{\text {command }}\right)$ of $15^{\circ}$ in dorsiflexion (DF) with constant velocity $(v)$ of $5 \%$ and hold time $\left(t_{\text {hold }}\right)$ of $1 \mathrm{~s}$. Raw traces of $(\mathbf{b})$ ankle angle and (d) torque resulting from each commanded positional perturbation taken from single representative subject with stroke, shown with initial $\left(\theta_{0}, \mathrm{~T}_{0}\right)$ and final $\left(\theta_{\infty}, \mathrm{T}_{\infty}\right)$ conditions for a single trace. (c) Steady-state torque ( $\left.\mathrm{T}_{\text {static }}\right)$ and angular displacement $\left(\theta_{\text {static }}\right)$ data are obtained by anklebot "slowly" stretching subject's ankle over passive range of motion in sagittal plane (right positive: DF, left negative: plantar flexion) and computing resultant net torque $\left(\mathrm{T}_{\infty}-\mathrm{T}_{0}\right)$ and angular displacement $\left(\theta_{\infty}-\theta_{0}\right)$ under static conditions. Data are then fitted with least-squares linear regression line in each direction within plane of movement, slope of which is estimate of passive ankle stiffness in that direction.

\section{Ankle Motor Control}

We calculated measures of ankle motor control from positional data recorded by the anklebot during unassisted trials [25]. These included averages for number of successful targeted passages, peak and mean speed, and normalized jerk. We considered a movement (or submovement) to have begun and terminated when the speed first rose above and dropped below 2 percent of the peak speed, respectively. We obtained movement speed and acceleration from the first and second derivatives of position; we used the speed profiles to calculate mean and peak speed. Movement smoothness was characterized by jerk; i.e., the 
average rate of change or first derivative of acceleration in a movement. In order to eliminate the effect of speed on movement smoothness, jerk was normalized to each subject's peak speed.

\section{Statistical Analyses}

We chose the number of subjects ( $n$ ) as sample of convenience. We computed group mean $\pm \mathrm{SD}$ at baseline, 3 wk, and termination (discharge). We used the Kolmogorov-Smirnov test to test for normality of distribution of data. For parametric data, we used paired $t$-tests to test for significant changes in any of the measures across the three time points; otherwise, we used the Wilcoxon sign rank test (Mann-Whitney U test). For nonparametric distribution, we reported the median. We computed correlations between two sets of data using the Pearson product-moment correlation $\left(r^{2}\right)$ if parametric and using Spearman rank order correlation $(\rho)$ if nonparametric. In addition, we ran multiple sample Kruskal-Wallis tests with nonparametric multiple comparisons. We set the significance level for comparison between two groups of data as well as correlations at $p<0.05$. The sample size used for all statistical tests was $n=8$.

\section{RESULTS}

Table 1 shows subject demographics and clinical outcomes at baseline. All eight subjects experienced their first unilateral stroke between 29 and 146 mo prior to enrollment (mean: $72.5 \mathrm{mo}$ ), well beyond the 6 mo threshold for designation of chronic phase of stroke; were between 43 and $75 \mathrm{yr}$ old (mean: $62.4 \mathrm{yr}$ ); had persistent lower-limb hemiparesis; had minimal resistance through ROM following catch (Modified Ashworth scores $\leq 2$ ) and at least trace active DF-PF at their paretic ankles; and walked overground at self-selected speeds between 27 and $114 \mathrm{~cm} / \mathrm{s}$ (mean: $51.4 \mathrm{~cm} / \mathrm{s}$ ). Six subjects used some type of assistive device for ambulation. All subjects successfully completed the training program.

\section{Muscle Activity During Passive Stretch}

Across subjects and across all trials, the mean EMG from both muscles did not significantly differ from the average $b$ EMG activity during passive stretches in both sagittal and frontal planes, which confirmed our assumption of "passivity." Further evidence for this was the fact that the average $b$ EMG was indistinguishable between the paretic and nonparetic limbs. Importantly, EMG during stretch at each sample was below its corresponding $b$ EMG \pm 1 SD that confirmed absence of stretch reflex activity.

\section{Changes in Paretic Passive Ankle Stiffness Following Training}

PAS data in each direction of movement and at each time point (baseline, $3 \mathrm{wk}$, and termination) were not distributed normally, necessitating the use of nonparametric statistics for comparison across time points. At baseline, the sagittal plane PAS was anisotropic, with significantly greater stiffness in DF $(53.4 \pm 8.2 \mathrm{Nm} / \mathrm{rad})$ than in PF

Table 1.

Characteristics of subjects with stroke.

\begin{tabular}{|c|c|c|c|c|c|c|c|}
\hline Subject & $\begin{array}{l}\text { Age } \\
(\mathbf{y r})\end{array}$ & Sex & $\begin{array}{c}\text { Time Poststroke } \\
\text { (mo) }\end{array}$ & $\begin{array}{l}\text { Paretic } \\
\text { Side }\end{array}$ & $\begin{array}{l}\text { Assistive } \\
\text { Device }\end{array}$ & $\begin{array}{l}\text { Baseline Speed* } \\
(\mathrm{cm} / \mathrm{s})\end{array}$ & $\begin{array}{c}\text { Modified Ashworth } \\
\text { Score }^{\dagger} \\
\text { (DF/PF) }\end{array}$ \\
\hline$\overline{1}$ & 75 & $\mathrm{M}$ & 146 & $\mathrm{R}$ & SPC & 114.4 & $0 / 0$ \\
\hline 2 & 73 & $\mathrm{~F}$ & 84 & $\mathrm{~L}$ & SPC & 28.7 & $1 / 1$ \\
\hline 3 & 60 & $\mathrm{~F}$ & 89 & $\mathrm{R}$ & AFO & 71.9 & $1 / 1$ \\
\hline 4 & 66 & M & 79 & $\mathrm{~L}$ & $\mathrm{AFO} / 4 \mathrm{PC}$ & 25.2 & $0 / 0$ \\
\hline 5 & 43 & $\mathrm{~F}$ & 60 & $\mathrm{~L}$ & - & 68.1 & $0 / 0$ \\
\hline 6 & 65 & $\mathrm{~F}$ & 29 & $\mathrm{~L}$ & $\mathrm{AFO} / \mathrm{SPC}$ & 26.7 & $2 / 1$ \\
\hline 7 & 64 & $\mathrm{~F}$ & 56 & $\mathrm{R}$ & - & 45.1 & $0 / 0$ \\
\hline 8 & 53 & $\mathrm{~F}$ & 37 & $\mathrm{R}$ & $\mathrm{AFO} / \mathrm{SPC}$ & 31.6 & $0 / 2$ \\
\hline Mean $\pm \mathrm{SD}$ & $62.4 \pm 10.4$ & - & $72.5 \pm 36.7$ & - & - & $51.4 \pm 31.4$ & $0-2$ \\
\hline
\end{tabular}


$(13.2 \pm 0.85 \mathrm{Nm} / \mathrm{rad}, p=0.001)$; however, this was not the case in the frontal plane, i.e., the stiffness did not significantly differ between EV $(51.6 \pm 7.5 \mathrm{Nm} / \mathrm{rad})$ and INV $(44.6 \pm 3.6 \mathrm{Nm} / \mathrm{rad}, p=0.72)$ directions. After $6 \mathrm{wk}$ of training, the PAS decreased in all four directions (DF, $\mathrm{PF}$, INV, and EV), but we observed statistically significant changes only in the sagittal plane PAS, i.e., DF and PF (Figure 4(a)). In one of those directions, i.e., DF, the PAS $(24.6 \pm 4.1 \mathrm{Nm} / \mathrm{rad})$ reverted into the ranges of young nondisabled subjects (DF: $12-48.2 \mathrm{Nm} / \mathrm{rad}$ ) as well as age-matched controls (DF: $22.4-53 \mathrm{Nm} / \mathrm{rad}$ ), whose data have been reported in a previous study [19]. In PF, however, the paretic PAS at termination (discharge) was outside the variability band of both young (10.7-25.5 Nm/rad) and age-matched nondisabled controls $(12.2-13.8 \mathrm{Nm} / \mathrm{rad})$ [19]. Similar to baseline, the PAS at discharge was anisotropic in the sagittal plane, i.e., significantly higher in DF $(24.6 \pm 4.1 \mathrm{Nm} / \mathrm{rad})$ than in PF $(10.0 \pm 0.47 \mathrm{Nm} / \mathrm{rad}, p=0.03)$, but not in the frontal plane (Figure 4(b)) - the stiffness did not significantly differ between EV $(40.8 \pm 8.6 \mathrm{Nm} / \mathrm{rad})$ and INV $(35.7 \pm 6.8 \mathrm{Nm} / \mathrm{rad}, p=0.72)$ directions. Importantly, no significant correlations (Spearman rank order coefficient) emerged between subjects' age and time poststroke versus changes in PAS in any direction.

\section{Relationship of Changes in Passive Ankle Stiffness with Gait Outcomes}

Following training, subjects significantly increased their self-selected overground walking speed through a combination of longer paretic STR lengths, faster cadence, and longer duration spent on paretic SST with concomitant decreases in DST duration [25]. However, spatial symmetry ${ }^{*}$ of gait did not change significantly, improving only in three of eight subjects. Correlation

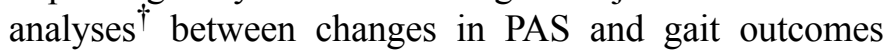
(Table 2) revealed that changes in passive PF stiffness were significantly correlated with changes in two key spatiotemporal parameters of gait function, namely (1) paretic STP length $(\rho=-0.88, p=0.03)$ and (2) paretic STR length $(\rho=-0.82, p=0.05)$, suggesting that improvements in paretic STR and paretic STP length

${ }^{*}$ We calculated spatial symmetry as [1-(paretic STP length/nonparetic STP length)].

${ }^{\dagger}$ Similar to PAS data, each gait variable was not normally distributed, necessitating the use of Spearman rank order correlation.
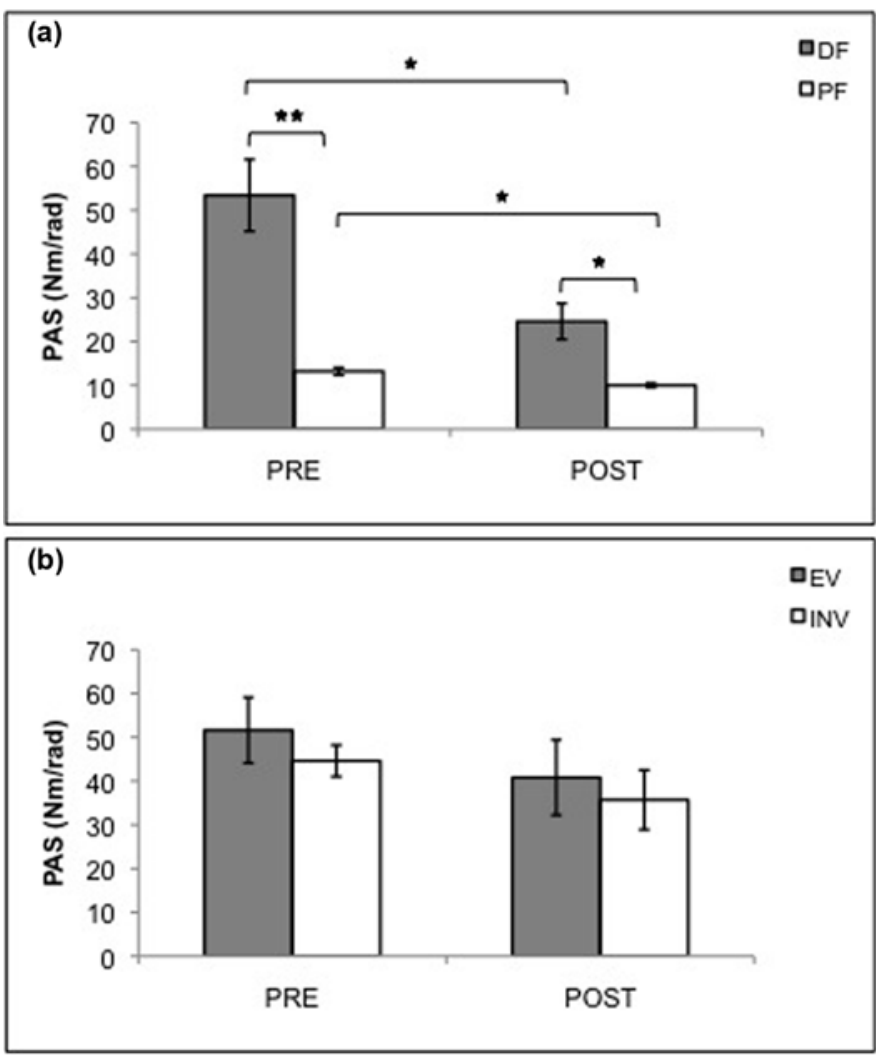

\section{Figure 4.}

Passive ankle stiffness (PAS) ( $\mathrm{Nm} / \mathrm{rad}$ ) in each direction at baseline (PRE) and at termination (POST). Although PAS decreased in both planes of movement (sagittal and frontal) posttraining, changes were significant only in trained degree of freedom, i.e., sagittal plane. (a) Changes in sagittal plane PAS i.e., dorsiflexion (filled) and plantar flexion (unfilled) across time (PRE vs POST). In both directions, PAS decreased posttraining $\left({ }^{*} p<0.05\right)$. PAS was anisotropic, i.e., higher in one direction versus another, at both time points, and this property was preserved across training with more pronounced difference between two directions at baseline $\left({ }^{* *} p<0.01\right)$. (b) Changes in frontal plane PAS, i.e., eversion (filled) and inversion (unfilled) across time (PRE vs POST). In both directions, PAS decreased posttraining but failed to achieve statistical significance. Unlike sagittal plane PAS, frontal plane PAS was not anisotropic at either time point.

occurred in part due to changes in the PF PAS that, in turn, contributed to improvements in overground gait speed. In both cases, the correlation was negative, indicating that subjects whose ankles became more compliant in PF with training took longer STPs and STRs on their paretic leg 


\section{Passive Ankle Stiffness in One Plane of Movement is Not Influenced by Coupled Movement in Orthogonal Plane}

During passive stretch in a given DOF (e.g., sagittal plane), movement in the orthogonal DOF (e.g., frontal plane) was left uncontrolled, i.e., the ankle was subject to synergistic movement in that DOF. The mechanical coupling (defined as the linear mapping between torques in one DOF to the resulting angular displacements in another DOF) may be represented as a compliance tensor. Each element of this tensor represents the ratio of angular displacement in one DOF to applied torque in an orthogonal DOF, and in particular, its off-diagonal terms represent the magnitude of cross-DOF coupling [19]. We found that the magnitude of coupling at rest across subjects was "weak" (lower by order[s] of magnitude compared with uncoupled, i.e., same DOF angle-to-torque compliances on the tensor diagonal). Notably, the coupling between DF and INV (vs DF and EV) and between PF and EV (vs PF and INV) was not weak, a finding consistent with our previous study [19]. As suggested by Roy et al., non-negligible cross-DOF coupling may be attributed to the inherent musculo-anatomical synergy between the sagittal and frontal planes [19]. For example, the ankle evertors (or invertors) play a role (albeit a weak one) as plantar flexors (or dorsiflexors) so one can expect appreciable coupling between INV (or EV) and DF (or PF) [19]. A deeper understanding of this cross-DOF coupling and a clearer interpretation of its potential relation to neurologic deficit would require direct evidence and is beyond the scope of the current study.

\section{Can Trends in Paretic Passive Ankle Stiffness be Attributed to Muscle Physiology?}

A primary finding of this study was that robotic training of the paretic ankle joint decreased its PAS in the sagittal plane; in one of those directions (DF), the PAS reverted into the ranges of younger and older nondisabled adults. Because of the long elapsed time since stroke, we assume that the ankle condition was stable and that the obtained improvements were not due to natural recovery. We considered the possibility that there might have been an underlying physiological basis for these changes. There is indirect evidence to link PAS to the summed physiological cross-sectional area (SPCA) and to the square of the mean moment arm of the antagonist group of muscles undergoing passive stretch [19]. It is possible that the robot-assisted, repetitive massed practice of the paretic ankle may have reduced the SPCA of plantar flex- ors as a whole and this, in turn, caused the passive DF stiffness to reduce over the course of training.

A surprising finding, however, was that PAS changed (though not significantly) in the frontal plane despite no targeted movements made or commanded (volitional or by the anklebot) during training in INV-EV. We believe that the changes seen in the frontal plane PAS could be explained by the synergistic role played by the plantar flexor muscles that are also evertors of the ankle. As an illustration, the peroneus brevis and peroneus longus muscles are the primary evertors of the ankle but are also (weak) plantar flexors. A reduction in the plantar flexor SPCA could, therefore, potentially contribute to a reduction in the overall SPCA of the evertors taken as a muscle group. If true, this in turn would lead to a decrease in INV PAS, a prediction consistent with the findings in this study. Similarly, the TA is the primary dorsiflexor but also acts to invert the ankle, so a reduction in the dorsiflexor SPCA could contribute to a reduction in the inverters as a group. If so, one would expect to see a reduction in the PF and EV PAS that is consistent with our experimental findings. However, without direct evidence of muscle morphological data, we acknowledge that these are simply qualitative lines of reasoning, i.e., the observed changes in PAS resulting due to our intervention may not be caused by the changes in muscle SPCA. In fact, the addition of robot-assisted practice in ankle movements in a population that likely does not have a normal level of use could potentially increase the SPCA through a hypertrophy effect. If such is the case, changes in SPCA, e.g., an increase in the SPCA of plantar flexors, cannot account for changes in PAS, e.g., a decrease in the DF direction.

\section{Training May Have Induced Intrinsic Changes Within Ankle Musculature}

It is plausible that the PAS in a given direction may have been altered due to changes within the ankle musculature in either (1) the cellular structure or (2) the fibertype distribution; however, the exact cause remains unclear without actual morphological muscle data. What could stimulate either (or both) of these mechanisms? We believe that this could be attributed to the large volume of robotic-driven exercise of the paretic ankle. It is known that exercise or training promotes a chronic increase in the so-called "collagen turnover" process in which collagen is broken down or degraded by as much as 50 percent [3637]. Changes induced by collagen turnover have been shown to modify the biomechanical (e.g., viscoelastic) 
[37] or structural (e.g., cross-sectional area) [37] properties of soft tissue, leading to altered resistance to loading [37]. Lieber et al. reported that a decrease in the collagen level led to a reduction in the ratio of collagen-to-muscle fiber tissue, thereby increasing muscle compliance [38].

An equally plausible conclusion is that repetitive exercise promoted changes in fiber-type distribution [39-42], i.e., an increase in the proportion of slow-to-fast twitch fibers; since the former type has a smaller diameter, it may have led to a decrease in the volume of the muscle undergoing passive stretching. Yet another possibility is that the PAS-altering mechanism was via changes in the thixotropic properties of antagonist muscles [43]. Yeh et al. suggested that the "gel component" of muscle (e.g., water and proteoglycans) may become less viscous after being stretched, resulting in lower PAS [44]. For this scenario to be credible, however, they rationalized that the muscle must not receive neural input because this may also modulate stiffness [44]. Because muscle activity measured using EMG has been shown to be negligible during passive stretch at these speeds [19], it is unlikely that neural mechanisms contributed to the PAS. While this rationale may explain the reduction of PAS in the DF and PF directions and appears to be consistent with other studies that attribute morphological and not just motoneuron transformations of spastic muscle over time [45], it fails to explain the changes in unexercised frontal plane PAS as reported here.

\section{Improvements in Walking Speed May be Attributed to Changes in Passive Ankle Stiffness}

A surprising and important finding that emerged was that the expected benefits of seated ankle training extended to whole-body function, such as overground gait speed and elements of gait, e.g., paretic SST and DST durations [25]. While this is certainly encouraging, it is contrary to our initial expectations and the concept of task-specificity of training. Given that subjects did not undergo gait training as part of our paradigm, we did not expect to see any improvements in overground gait and its constituent spatiotemporal parameters. It is unclear as to the exact cause(s) for the increases seen in gait speed. One possibility is that changes in paretic PAS could have potentially contributed to the increases in gait speed by means of increased STR and STP lengths on the paretic leg. Previous studies have shown, for example, that the active component of ankle stiffness varies with measures of mobility function, e.g., gait speed in nondisabled individuals [46]. Evidence also exists that PAS in the sagittal plane adds a unique contribution to walking speed in sub- jects with diabetes and peripheral neuropathy $[8,34]$. This appears to be true in chronic stroke as well; in this study, we found a strong and significant correlation between changes in PF PAS with improvements in paretic STP and paretic STR lengths during unassisted overground gait. Because passive stiffness contributes to the total mechanical impedance of the joint, it is not inconceivable that these changes, in turn, may have enabled subjects to use their paretic ankle to position their foot more efficiently, thereby increasing their paretic STP and paretic STR lengths. For example, dorsiflexor control of the foot is essential to clear the ground during the swing phase of gait and for ecological landing. Changes in passive mechanisms such as reduction in the DF PAS would contribute to a reduction in the total mechanical impedance of the ankle (in DF) that may lead to better dorsiflexor control of the foot for greater swing clearance, as well as controlled landing. Similarly, the plantar flexors play a critical role in stabilizing the forefoot rocker action during terminal stance, and we know that plantar flexor muscletendons generate the largest power burst during trailing leg push-off [47-49]. The plantar flexor muscle-tendons are known to perform nearly 35 percent of the total lower-limb positive mechanical work and as much as 66 percent of the total ankle muscle-tendon positive work [50] in a single STR to enable forward propulsion. Therefore, a reduction in the total mechanical impedance in $\mathrm{PF}$ could in fact lead to increased anterior-posterior (A/P) positive propulsion during paretic SST. Indeed, our previous study with the same subjects [25] reported that a sub-set of the population (4 out of 5 subjects) increased their $\mathrm{A} / \mathrm{P}$ positive propulsion by as much as 18 percent during the paretic SST phase.

\section{Contribution of Neural Versus Mechanical/Muscle Physiology Factors}

Although significant correlations emerged between changes in PF PAS and paretic STP length and paretic STR length (greater decreases in stiffness correlated with longer STPs and STRs), we need to interpret this finding with caution. Hemiparetic gait is often characterized by an asymmetry in which the paretic leg takes the longer STP, so it is not clear whether an increase in STP length is actually beneficial. Indeed, as reported in Forrester et al. [25], changes in paretic STP length did not contribute to improvement in independent floor-walking speed. Here, we investigated this issue further and found that changes in PF PAS did not influence changes in spatial gait symmetry. This raises the possibility that improvements in 
PAS and gait function are not causal but rather a secondary correlation facilitated by some other causal relationship; that is, there might instead be a neural training effect that leads to better ankle motor control being responsible for the observed performance gains in gait function rather than resulting solely from changes to passive tissue. This is quite conceivable - after all, our training was an active (interactive) process in which the anklebot did not serve as a passive motion machine and it is doubtful that the training outcomes reported here would have been replicated by a passive stretching routine with the same number of movements. Indeed, short-term motor skill ankle training has been shown to increase cortical excitability to the TA that equal amounts of unskilled and passive ankle training do not [51]. The increased excitability has been associated with reduced errors on an ankle motor performance task, suggestive of improved motor control of ankle musculature [51]. If a similar mechanism is evoked by the anklebot training in our subjects, this may be the primary contributor to improved walking speeds reported in Forrester et al. [25].

Our correlation analysis revealed that decreases in DST duration (indicative of improved dynamic balance control during gait) were highly correlated with improved ankle motor control, in particular movement speed and smoothness. Subjects with higher gains in speed and smoothness of ankle targeting on the visuomotor task spent less time in double stance and vice versa. However, the lack of correlation between changes in paretic STP and paretic STR length to changes in any of the motor control metrics suggest that both neural and mechanical factors contributed to improvements in walking function. It appears that improved paretic ankle motor control and changes to passive tissue contributed independently by improving distinct elements of walking function; the former positively affected a key temporal element of walking, i.e., DST duration, while the latter improved spatial aspects of walking, i.e., STP and STR lengths.

\section{Baseline Passive Ankle Stiffness May be Predictor of Improvements in Walking Function}

Subjects with higher PAS in PF and lower PAS in EV showed greater improvements in walking function, specifically, paretic STR length, paretic STP length, paretic SST duration, and cadence. This may be of importance in identifying potential responders, especially to this type of intervention; however, the small sample size prevents an in-depth analysis of the predictive value of PAS. A sub- ject-by-subject qualitative analysis does, however, reveal the underlying trends between baseline PAS and functional outcomes; for example, the two subjects with the highest PF PAS at baseline (subjects 2 and 8, respectively) also showed the greatest relative change in overground walking speed (118.6\% and $27.4 \%$, respectively), reflecting the positive correlation. This change was clinically significant as well in that their ambulation level (defined with respect to unassisted floor walking speed) changed; both subjects transitioned from home (HC) $(<40 \mathrm{~cm} / \mathrm{s})$ to limited community (LC) $(40-80 \mathrm{~cm} / \mathrm{s})$ ambulators. Conversely, the subject with the most compliant ankle in PF at baseline (subject 7) improved the least in gait speed $(15 \%)$ with no change in ambulation category. We also observed similar trends reflecting a negative correlation between baseline PAS in EV and functional outcomes; the subject with the most compliant ankle in EV (subject 2) improved the most in gait speed (118.6\%), transitioning from $\mathrm{HC}$ to LC ambulator, while the subject with the least compliant ankle in EV (subject 7) improved the least $(15 \%)$, with no change in ambulation category.

\section{Comparison with Previous Related Work}

To the best of our knowledge, this is the first study to report changes in frontal plane PAS in people with chronic stroke. Independent training of the ankle joint is not a unique idea. For example, Mirelman et al. employed a different device and delivered visually guided and intentiondriven training in the seated position, requiring subjects to attempt to make targeted movements [52]. Of the groups that measured stiffness, most employed passive stretching of the paretic ankle, e.g., PMS, and measurements in all those studies were made exclusively in the sagittal plane. For instance, Selles et al. investigated the effect of repeated feedback-controlled and programmed "intelligent" stretching of the ankle plantar flexors and dorsiflexors as a potential method to treat subjects with ankle spasticity and/or contracture in stroke and found significant improvements in paretic PAS in DF from a 4 wk intervention [23]. Yeh et al. quantified the immediate effect of PMS on the inhibition of ankle hypertonia in subjects with hemiplegia and ankle plantar flexor hypertonia [44]. Bressel and McNair used a slow, prolonged static and cyclic calf stretching of $30 \mathrm{~min}$ duration in patients with stroke to compare its short-term effects on PAS and reported a decrease in paretic PAS [22]. Generally speaking, the training-induced changes in sagittal plane PAS reported here differed from those published by others (Table 3). 
Table 3.

Comparison of changes in passive ankle stiffness in this study (anklebot) with published literature.

\begin{tabular}{|c|c|c|c|c|}
\hline Criterion/Study & Equipment & $\begin{array}{l}\text { Experimental } \\
\text { Conditions }\end{array}$ & $\begin{array}{c}\text { Perturbation } \\
\text { Characteristics }\end{array}$ & $\begin{array}{c}\% \Delta_{\text {rel }} K^{*} \\
(p-\text { Value, } \alpha=0.05)\end{array}$ \\
\hline \multicolumn{5}{|l|}{ At $5 \mathrm{Nm}$ Torque } \\
\hline Selles et al., 2005 [23] & $\begin{array}{l}\text { Custom stretching } \\
\text { device }\end{array}$ & $\begin{array}{l}\text { Knee flexed }\left(30^{\circ}\right) \\
3 \text { sessions } / \mathrm{wk} \\
45 \mathrm{~min} / \mathrm{session}\end{array}$ & $\begin{array}{l}30 \% \mathrm{~s}, 10-25 \mathrm{Nm}^{\dagger}(\mathrm{DF}) \\
5-10 \mathrm{Nm}^{\dagger}(\mathrm{PF}), 5 \mathrm{~s} \text { hold }\end{array}$ & $\begin{array}{l}\text { DF: }-38.8^{+} \\
\text {PF: } 31.0^{*}\end{array}$ \\
\hline Anklebot & 2-DOF ankle robot & $\begin{array}{l}\text { Knee flexed }\left(60^{\circ}\right) \\
1 \mathrm{session} / \mathrm{wk} \\
\sim 15 \mathrm{~min} / \mathrm{session}\end{array}$ & $\begin{array}{l}5 \% \text { s, ROH, 0-PROM (DF), } \\
0-20^{\circ}(\mathrm{PF}), 1 \mathrm{~s} \text { hold }\end{array}$ & $\begin{array}{l}\text { DF: }-24.8^{\ddagger} \\
\text { PF: } 5.5\end{array}$ \\
\hline \multicolumn{5}{|l|}{ Within ROM } \\
\hline Selles et al., 2005 [23] & $\begin{array}{l}\text { Custom stretching } \\
\text { device }\end{array}$ & $\begin{array}{l}\text { Knee flexed }\left(30^{\circ}\right) \\
3 \text { sessions } / \mathrm{wk} \\
45 \mathrm{~min} / \mathrm{session}\end{array}$ & $\begin{array}{l}30 \% \text { s, 10-25 Nm }{ }^{\dagger}(\mathrm{DF}) \\
5-10 \mathrm{Nm}^{\dagger}(\mathrm{PF}), 5 \mathrm{~s} \text { hold }\end{array}$ & $\begin{array}{l}\text { DF: }-36.36^{\star} \\
\text { PF: } 28.57^{\star}\end{array}$ \\
\hline Anklebot & 2-DOF ankle robot & $\begin{array}{l}\text { Knee flexed }\left(60^{\circ}\right) \\
1 \mathrm{session} / \mathrm{wk}, \\
\sim 15 \mathrm{~min} / \mathrm{session}\end{array}$ & $\begin{array}{l}5 \% \text { s, ROH, 0-PROM (DF), } \\
0-20^{\circ}(\mathrm{PF}), 1 \mathrm{~s} \text { hold }\end{array}$ & $\begin{array}{l}\text { DF }:-32.69 \\
\text { PF }:-13.46\end{array}$ \\
\hline \multicolumn{5}{|l|}{ At Neutral } \\
\hline Selles et al., 2005 [23] & $\begin{array}{l}\text { Custom stretching } \\
\text { device }\end{array}$ & $\begin{array}{c}\text { Knee flexed }\left(30^{\circ}\right) \text {, } \\
3 \text { sessions } / w k \\
45 \mathrm{~min} / \mathrm{session}\end{array}$ & $\begin{array}{l}30 \% \mathrm{~s}, 10-25 \mathrm{Nm}^{\dagger}(\mathrm{DF}) \\
5-10 \mathrm{Nm}^{\dagger}(\mathrm{PF}), 5 \mathrm{~s} \text { hold }\end{array}$ & $-31.81^{\ddagger}$ \\
\hline Anklebot & 2-DOF ankle robot & $\begin{array}{l}\text { Knee flexed }\left(60^{\circ}\right) \\
1 \mathrm{session} / \mathrm{wk} \\
\sim 15 \mathrm{~min} / \mathrm{session}\end{array}$ & $\begin{array}{l}5 \% \text { s, ROH, 0-PROM (DF), } \\
0-20^{\circ}(\mathrm{PF}), 1 \mathrm{~s} \text { hold }\end{array}$ & $-14.73^{\dagger}$ \\
\hline \multicolumn{5}{|l|}{ Within DF Range } \\
\hline Yeh et al., 2004 [44] & Custom device & $\begin{array}{l}\text { Supine, } \\
30 \mathrm{~min} / \mathrm{session}\end{array}$ & $\begin{array}{l}\text { Sinusoidal PMS, } \\
\pm 3^{\circ} \text { amplitude, } \\
1-15 \mathrm{~Hz} \text { frequency, } \\
\text { Assessment: } 5^{\circ} / \mathrm{s} \\
\text { PROM-DF }\end{array}$ & -48.51 to -42.69 t \\
\hline $\begin{array}{l}\text { Bressel \& McNair, } \\
\quad 2002 \text { [22] }\end{array}$ & Kim-Com dynamometer & Single session & $\begin{array}{l}\text { CPM for } 60 \mathrm{~s} \text {, } \\
0 \%-80 \% \max \mathrm{ROM}\end{array}$ & $\begin{array}{l}\text { Static: }-34.67 \\
\text { Cyclical: }-29.87\end{array}$ \\
\hline Anklebot & 2-DOF ankle robot & $\begin{array}{l}\text { Knee flexed }\left(60^{\circ}\right) \\
1 \text { session } / \mathrm{wk}, \\
\sim 15 \mathrm{~min} / \mathrm{session}\end{array}$ & $\begin{array}{l}5 \% / \mathrm{s}, \mathrm{ROH}, 0-\mathrm{PROM}(\mathrm{DF}) \\
0-20^{\circ}(\mathrm{PF}), 1 \mathrm{~s} \text { hold }\end{array}$ & -66.74 \\
\hline \multicolumn{5}{|c|}{$\begin{array}{l}\text { "Relative change in variable between pre- and postintervention. } \\
\text { †Peak torque. } \\
\text { TStatistically significant differences }(p<0.05) . \\
\text { ॠAt sinusoidal } 3 \mathrm{~Hz} \text { frequency. } \\
\mathrm{CPM}=\text { continuous passive motion, } \mathrm{DF}=\text { dorsiflexion, } \mathrm{DOF}=\text { degrees of freedom, } \mathrm{PF}=\text { plantar flexion, } \mathrm{PMS}=\text { prolonged muscle stretch, } \mathrm{PROM}=\text { passive range of } \\
\text { motion, } \mathrm{ROH}=\text { ramp-and-hold position perturbation, } \mathrm{ROM}=\text { range of motion. }\end{array}$} \\
\hline
\end{tabular}

Specifically, the reductions in paretic PAS in DF were-

1. Lower than those obtained by Selles et al. Since the mean time poststroke in Selles et al.'s $(7.7 \pm 6.6 \mathrm{yr})$ and our $(6.04 \pm 3.05 \mathrm{yr})$ studies was similar, the difference may be due to the sample age because Selles et al.'s study consisted of relatively younger patients with stroke $(54.6 \pm 9.1 \mathrm{yr})$ than our subjects $(62.4 \pm 10.4 \mathrm{yr})$.

2. Higher than those reported in Yeh et al.'s and Bressel and McNair's studies. Of notice, the PAS in Yeh et al.'s study was measured in a supine position.
Finally, it is worthwhile to point out that our success in PAS measurement of the paretic ankle in multiple DOFs parallel those for the upper limb, e.g., wrist [5355] and arm [56], which could ultimately provide us with a clearer understanding of how the nervous system may take advantage of the direction(s) of higher compliance, albeit differently for the two cases.

\section{Study Limitations}

We have to interpret our results with caution. This was a pilot study that investigated the changes in PAS at 
the hemiparetic ankle resulting from a 6 wk seated visuomotor training using an impedance-controlled modular ankle robot. The sample size is small, limiting conclusions about ability to generalize the results. Because the number of subjects was chosen as a sample of convenience, we did not have information on statistical power available a priori. However, we did perform retrospective (post hoc) power analysis on PAS changes in those directions in which the baseline-termination changes were not statistically significant, i.e., EV and INV PAS. Our results showed that the minimum sample size needed to observe detectable differences and statistical significance was $n=11$, which is not appreciably higher than the sample size in this study $(n=8)$. Also, despite not seeing correlations between changes in frontal plane PAS and gait function, those may emerge through improved motor control of the mediolateral stabilizer muscles if training was also conducted in the frontal plane. Furthermore, we did not collect follow-up data beyond the 6 wk period, limiting our ability to comment on the long-term retention of changes in PAS.

\section{Clinical Implications}

We are not claiming that training in the seated position is optimal. One might speculate that training both ankle control and task-oriented locomotor function might lead to even superior outcomes, and further testing is needed to elucidate the potential of each approach. Nonetheless, we were encouraged by the surprising result of meaningful functional gait changes that suggest that ankle training can positively affect locomotor function, possibly by means of changes in PAS leading to more efficient placement of foot and interlimb weight transfer during stance, and such paradigms might allow us to initiate training even sooner when the patient is unable to stand. Future studies are underway to measure PAS in people with stroke during the earlier stages of stroke recovery (subacute phase) and monitor changes in PAS resulting from the seated training paradigm in comparison with age-matched controls.

\section{CONCLUSIONS}

We presented pilot findings on the changes in PAS in the hemiparetic ankle after $6 \mathrm{wk}$ of anklebot-assisted interactive therapy in people with chronic stroke. Our findings were that a performance-based, progressive intervention that focuses on training the hemiparetic ankle not only decreases the PAS in PF and DF directions, but in fact reverts the PAS in the latter direction into the ranges of age-matched, nondisabled individuals. Even more important was the fact that increased compliance of the paretic ankle contributed to improvements in the quality of unassisted overground walking and that baseline PAS emerged to be a predictor of improvements in key spatiotemporal parameters of independent floor walking. We believe that these results constitute a firstof-its kind evidence that bridges the gap between an important and quantifiable measure of diseased ankle pathology and a whole-body functional task, i.e., gait. Future studies will use the anklebot to measure the (1) total mechanical impedance, i.e., passive plus active and other dynamic factors of the paretic ankle; (2) frontal plane PAS after training INV-EV movements; and (3) PAS in patients in the subacute phase of recovery, as well as in neurological populations besides stroke.

\section{ACKNOWLEDGMENTS}

\section{Author Contributions:}

Study concept and design: A. Roy, L. W. Forrester, R. F. Macko, H. I. Krebs.

Acquisition of data: A. Roy.

Analysis and interpretation of data: A. Roy, L. W. Forrester, R. F. Macko, H. I. Krebs.

Drafting of manuscript: A. Roy.

Critical revision of manuscript for important intellectual content: A. Roy, L. W. Forrester, H. I. Krebs.

Obtained funding: L. W. Forrester, R. F. Macko.

Study supervision: L. W. Forrester, R. F. Macko.

Financial Disclosures: Drs. Roy, Forrester, and Macko have declared that no competing interests exist. Dr. Krebs is a co-inventor in MITheld patents for the robotic technology and holds equity positions in Interactive Motion Technologies Inc, the company that manufactures this type of technology under license to MIT. Dr. Krebs was involved in study concept and design, analysis and interpretation of data, and critical revisions of the manuscript for important intellectual content but played no role in study funding.

Funding/Support: This material was based on work supported by the VA Rehabilitation Research and Development Service (grant B2294T) and the Baltimore VAMC Center of Excellence on TaskOriented Exercise and Robotics in Neurological Diseases (grant B3688R).

Additional Contributions: The authors acknowledge the Baltimore VAMC GRECC as the site of conduct for the clinical research.

Institutional Review: Recruitment and informed consent procedures were approved by the University of Maryland Institutional Review Board, the Baltimore VA Research and Development Committee, and 
the MIT Committee on the Use of Humans as Experimental Subjects. All subjects gave informed consent prior to their inclusion in the study. Participant Follow-Up: The authors do not plan to inform participants of the publication of this study. Participants met with the investigators to discuss the insights from their individual training sessions.

Disclaimer: The views expressed by the authors are their own and not necessarily the official policy of the VA.

\section{REFERENCES}

1. Roger VL, Go AS, Lloyd-Jones DM, Adams RJ, Berry JD, Brown TM, Carnethon MR, Dai S, de Simone G, Ford ES, Fox CS, Fullerton HJ, Gillespie C, Greenlund KJ, Hailpern SM, Heit JA, Ho PM, Howard VJ, Kissela BM, Kittner SJ, Lackland DT, Lichtman JH, Lisabeth LD, Makuc DM, Marcus GM, Marelli A, Matchar DB, McDermott MM, Meigs JB, Moy CS, Mozaffarian D, Mussolino ME, Nichol G, Paynter NP, Rosamond WD, Sorlie PD, Stafford RS, Turan TN, Turner MB, Wong ND, Wylie-Rosett J; American Heart Association Statistics Committee and Stroke Statistics Subcommittee. Heart disease and stroke statistics2011 update: a report from the American Heart Association. Circulation. 2011;123(4):e18-209. [PMID:21160056] http://dx.doi.org/10.1161/CIR.0b013e3182009701

2. Bahlsen HA, Nigg BM. Influence of attached masses on impact forces and running style in heel-toe running. Int $\mathrm{J}$ Sport Biomech. 1987;3(3):264-75.

3. McGowan CP, Neptune RR, Kram R. Independent effects of weight and mass on plantar flexor activity during walking: implications for their contributions to body support and forward propulsion. J Appl Phys. 2008;105(2):486-94. [PMID:18556431]

http://dx.doi.org/10.1152/japplphysiol.90448.2008

4. Ferris DP, Farley CT. Interaction of leg stiffness and surface stiffness during human hopping. J Appl Physiol. 1997; 82(1):15-22. [PMID:9029193]

5. Ferris DP, Louie M, Farley CT. Running in the real world: adjusting leg stiffness for different surfaces. Proc Biol Sci. 1998;265(1400):989-94. [PMID:9675909] http://dx.doi.org/10.1098/rspb.1998.0388

6. Hansen AH, Childress DS, Miff SC, Gard SA, Mesplay KP. The human ankle during walking: implications for design of biomimetic ankle prostheses. J Biomech. 2004;37(10): 1467-74. [PMID:15336920] http://dx.doi.org/10.1016/j.jbiomech.2004.01.017

7. Lark SD, Buckley JG, Bennett S, Jones D, Sargeant AJ. Joint torques and dynamic joint stiffness in elderly and young men during stepping down. Clin Biomech (Bristol, Avon). 2003;18(9):848-55. [PMID:14527812] http://dx.doi.org/10.1016/S0268-0033(03)00150-5

8. Salsich GB, Mueller MJ, Sahrmann SA. Passive ankle stiffness in subjects with diabetes and peripheral neuropathy versus an age-matched comparison group. Phys Ther. 2000;80(4):352-62. [PMID:10758520]

9. Tabary JC, Tabary C, Tardieu C, Tardieu G, Goldspink G. Physiological and structural changes in the cat's soleus muscle due to immobilization at different lengths by plaster casts. J Physiol. 1972;224(1):231-44. [PMID:5039983]

10. Halar EM, Stolov WC, Venkatesh B, Brozovich FV, Harley JD. Gastrocnemius muscle belly and tendon length in stroke patients and able-bodied persons. Arch Phys Med Rehabil. 1978;59(10):476-84. [PMID:718411]

11. Magid A, Law DJ. Myofibrils bear most of the resting tension in frog skeletal muscle. Science. 1985;230(4731): 1280-82. [PMID:4071053]

http://dx.doi.org/10.1126/science.4071053

12. Wang K, McCarter R, Wright J, Beverly J, Ramirez-Mitchell R. Regulation of skeletal muscle stiffness and elasticity by titin isoforms: a test of the segmental extension model of resting tension. Proc Natl Acad Sci USA. 1991; 88(16):7101-5. [PMID:1714586] http://dx.doi.org/10.1073/pnas.88.16.7101

13. Chung SG, Van Rey E, Bai Z, Roth EJ, Zhang LQ. Biomechanic changes in passive properties of hemiplegic ankles with spastic hypertonia. Arch Phys Med Rehabil. 2004; 85(10):1638-46. [PMID:15468024] http://dx.doi.org/10.1016/j.apmr.2003.11.041

14. Harlaar J, Becher JG, Snijders CJ, Lankhorst GJ. Passive stiffness characteristics of ankle plantar flexors in hemiplegia. Clin Biomech (Bristol, Avon). 2000;15(4):261-70. [PMID:10675667] http://dx.doi.org/10.1016/S0268-0033(99)00069-8

15. Hufschmidt A, Mauritz KH. Chronic transformation of muscle in spasticity: a peripheral contribution to increased tone. J Neurol Neurosurg Psychiatry. 1985;48(7):676-85. [PMID:4031912] http://dx.doi.org/10.1136/jnnp.48.7.676

16. Katz RT, Rovai GP, Brait C, Rymer WZ. Objective quantification of spastic hypertonia: correlation with clinical findings. Arch Phys Med Rehabil. 1992;73(4):339-47. [PMID:1554307]

17. Katz RT, Rymer WZ. Spastic hypertonia: mechanisms and measurement. Arch Phys Med Rehabil. 1989;70(2):144-55. [PMID:2644919]

18. Thilmann AF, Fellows SJ, Ross HF. Biomechanical changes at the ankle joint after stroke. J Neurol Neurosurg Psychiatry. 1991;54(2):134-39. [PMID:2019838] http://dx.doi.org/10.1136/jnnp.54.2.134

19. Roy A, Krebs HI, Bever CT, Forrester LW, Macko RF, Hogan N. Measurement of passive ankle stiffness in subjects with chronic hemiparesis using a novel ankle robot. J Neurophysiol. 2011;105(5):2132-49. [PMID:21346215] http://dx.doi.org/10.1152/jn.01014.2010 
20. Odéen I. Reduction of muscular hypertonus by long-term muscle stretch. Scand J Rehabil Med. 1981;13(2-3):93-99. [PMID:7345572]

21. Tsai KH, Yeh CY, Chang HY, Chen JJ. Effects of a single session of prolonged muscle stretch on spastic muscle of stroke patients. Proc Natl Sci Counc Repub China B. 2001; 25(2):76-81. [PMID:11370763]

22. Bressel E, McNair PJ. The effect of prolonged static and cyclic stretching on ankle joint stiffness, torque relaxation, and gait in people with stroke. Phys Ther. 2002;82(9):880-87. [PMID:12201802]

23. Selles RW, Li X, Lin F, Chung SG, Roth EJ, Zhang LQ. Feedback-controlled and programmed stretching of the ankle plantarflexors and dorsiflexors in stroke: effects of a 4-week intervention program. Arch Phys Med Rehabil. 2005;86(12):2330-36. [PMID:16344031] http://dx.doi.org/10.1016/j.apmr.2005.07.305

24. Roy A, Krebs HI, Williams DJ, Bever CT, Forrester LW, Macko RM, Hogan N. Robot-aided neurorehabilitation: A robot for ankle rehabilitation. IEEE Trans Robot. 2009; 25(3):569-82.

http://dx.doi.org/10.1109/TRO.2009.2019783

25. Forrester LW, Roy A, Krebs HI, Macko RF. Ankle training with a robotic device improves hemiparetic gait after a stroke. Neurorehabil Neural Repair. 2011;25(4):369-77.

[PMID:21115945]

http://dx.doi.org/10.1177/1545968310388291

26. Aisen ML, Krebs HI, Hogan N, McDowell F, Volpe BT. The effect of robot-assisted therapy and rehabilitative training on motor recovery following stroke. Arch Neurol. 1997;54(4):443-46. [PMID:9109746] http://dx.doi.org/10.1001/archneur.1997.00550160075019

27. Volpe BT, Krebs HI, Hogan N, Edelstein OTR L, Diels CM, Aisen M. A novel approach to stroke rehabilitation: robot-aided sensorimotor stimulation. Neurology. 2000; 54(10):1938-44. [PMID:10822433] http://dx.doi.org/10.1212/WNL.54.10.1938

28. Krebs HI, Volpe BT, Ferraro M, Fasoli S, Palazzolo J, Rohrer B, Edelstein L, Hogan N. Robot-aided neurorehabilitation: from evidence-based to science-based rehabilitation. Top Stroke Rehabil. 2002;8(4):54-70.

[PMID:14523730]

http://dx.doi.org/10.1310/6177-QDJJ-56DU-0NW0

29. Ferraro M, Palazzolo JJ, Krol J, Krebs HI, Hogan N, Volpe BT. Robot-aided sensorimotor arm training improves outcome in patients with chronic stroke. Neurology. 2003; 61(11):1604-7. [PMID:14663051] http://dx.doi.org/10.1212/01.WNL.0000095963.00970.68

30. Fasoli SE, Krebs HI, Stein J, Frontera WR, Hogan N. Effects of robotic therapy on motor impairment and recovery in chronic stroke. Arch Phys Med Rehabil. 2003;
84(4):477-82. [PMID:12690583]

http://dx.doi.org/10.1053/apmr.2003.50110

31. Volpe BT, Lynch D, Rykman-Berland A, Ferraro M, Galgano M, Hogan N, Krebs HI. Intensive sensorimotor arm training mediated by therapist or robot improves hemiparesis in patients with chronic stroke. Neurorehabil Neural Repair. 2008;22(3):305-10. [PMID:18184932] http://dx.doi.org/10.1177/1545968307311102

32. Stein J, Krebs HI, Frontera WR, Fasoli SE, Hughes R, Hogan N. Comparison of two techniques of robot-aided upper limb exercise training after stroke. Am J Phys Med Rehabil. 2004;83(9):720-28. [PMID:15314537] http://dx.doi.org/10.1097/01.PHM.0000137313.14480.CE

33. Lo AC, Guarino PD, Richards LG, Haselkorn JK, Wittenberg GF, Federman DG, Ringer RJ, Wagner TH, Krebs HI, Volpe BT, Bever CT Jr, Bravata DM, Duncan PW, Corn BH, Maffucci AD, Nadeau SE, Conroy SS, Powell JM, Huang GD, Peduzzi P. Robot-assisted therapy for longterm upper-limb impairment after stroke. N Engl J Med. 2010;362(19):1772-83. [PMID:20400552]

http://dx.doi.org/10.1056/NEJMoa0911341

34. Salsich GB, Mueller MJ. Effect of plantar flexor muscle stiffness on selected gait characteristics. Gait Posture. 2000;11(3):207-16. [PMID:10802433] http://dx.doi.org/10.1016/S0966-6362(00)00047-3

35. Lamontagne A, Voigt M, Larsen K, Sinkjær T. Early and late components of the quadriceps stretch reflex in human. Proceedings of 26th Society for Neuroscience Annual Meeting; 2000 Nov 4-9; New Orleans, LA.

36. Miller BF, Olesen JL, Hansen M, Døssing S, Crameri RM, Welling RJ, Langberg H, Flyvbjerg A, Kjaer M, Babraj JA, Smith K, Rennie MJ. Coordinated collagen and muscle protein synthesis in human patella tendon and quadriceps muscle after exercise. J Physiol. 2005;567(Pt 3):1021-33. [PMID:16002437] http://dx.doi.org/10.1113/jphysiol.2005.093690

37. Kjaer M, Langberg H, Miller BF, Boushel R, Crameri R, Koskinen S, Heinemeier K, Olesen JL, Døssing S, Hansen M, Pedersen SG, Rennie MJ, Magnusson P. Metabolic activity and collagen turnover in human tendon in response to physical activity. J Musculoskelet Neuronal Interact. 2005;5(1):41-52. [PMID:15788870]

38. Lieber RL, Steinman S, Barash IA, Chambers H. Structural and functional changes in spastic skeletal muscle. Muscle Nerve. 2004;29(5):615-27. [PMID:15116365]

http://dx.doi.org/10.1002/mus.20059

39. Gollnick PD, Armstrong RB, Saubert CW 4th, Piehl K, Saltin B. Enzyme activity and fiber composition in skeletal muscle of untrained and trained men. J Appl Physiol. 1972; 33(3):312-19. [PMID:4403464]

40. Costill DL, Daniels J, Evans W, Fink W, Krahenbuhl G, Saltin B. Skeletal muscle enzymes and fiber composition in 
male and female track athletes. J Appl Physiol. 1976;40(2): 149-54. [PMID:129449]

41. Fink WJ, Costill DL, Pollock ML. Submaximal and maximal working capacity of elite distance runners. Part II. Muscle fiber composition and enzyme activities. Ann N Y Acad Sci. 1977;301:323-27. [PMID:270925] http://dx.doi.org/10.1111/j.1749-6632.1977.tb38210.x

42. Saltin B, Henriksson J, Nygaard E, Andersen P, Jansson E. Fiber types and metabolic potentials of skeletal muscles in sedentary man and endurance runners. Ann N Y Acad Sci. 1977;301:3-29. [PMID:73362] http://dx.doi.org/10.1111/j.1749-6632.1977.tb38182.x

43. Enoka RM. Acute adjustments. In: Enoka RM, editor. Neuromechanics of human movement. 3rd ed. Champaign (IL): Human Kinetics; 2002. p. 383.

44. Yeh CY, Chen JJ, Tsai KH. Quantitative analysis of ankle hypertonia after prolonged stretch in subjects with stroke. J Neurosci Methods. 2004;137(2):305-14. [PMID:15262075] http://dx.doi.org/10.1016/j.jneumeth.2004.03.001

45. Dietz V, Ketelsen UP, Berger W, Quintern J. Motor unit involvement in spastic paresis. Relationship between leg muscle activation and histochemistry. J Neurol Sci. 1986; 75(1):89-103. [PMID:3746341] http://dx.doi.org/10.1016/0022-510X(86)90052-3

46. Palmer M. Sagittal plane characterization of normal human ankle function across a range of walking gait speeds [thesis]. [Cambridge (MA)]: Massachusetts Institute of Technology; 2002.

47. Eng JJ, Winter DA. Kinetic analysis of the lower limbs during walking: what information can be gained from a threedimensional model? J Biomech. 1995;28(6):753-58. [PMID:7601875] http://dx.doi.org/10.1016/0021-9290(94)00124-M

48. Gitter A, Czerniecki JM, DeGroot DM. Biomechanical analysis of the influence of prosthetic feet on below-knee amputee walking. Am J Phys Med Rehabil. 1991;70(3): 142-48. [PMID:2039616] http://dx.doi.org/10.1097/00002060-199106000-00006

49. Meinders M, Gitter A, Czerniecki JM. The role of ankle plantar flexor muscle work during walking. Scand J Rehabil Med. 1998;30(1):39-46. [PMID:9526753]

50. Sawicki GS, Ferris DP. Powered ankle exoskeletons reveal the metabolic cost of plantar flexor mechanical work during walking with longer steps at constant step frequency. J Exp Biol. 2009;212(Pt 1):21-31. [PMID:19088207] http://dx.doi.org/10.1242/jeb.017269
51. Perez MA, Lungholt BK, Nyborg K, Nielsen JB. Motor skill training induces changes in the excitability of the leg cortical area in healthy humans. Exp Brain Res. 2004; 159(2):197-205. [PMID:15549279]

http://dx.doi.org/10.1007/s00221-004-1947-5

52. Mirelman A, Bonato P, Deutsch JE. Effects of training with a robot-virtual reality system compared with a robot alone on the gait of individuals after stroke. Stroke. 2009;40(1): 169-74. [PMID:18988916] http://dx.doi.org/10.1161/STROKEAHA.108.516328

53. Charles SK, Hogan N. Dynamics of wrist rotations. J Biomech. 2011;44(4):614-21. [PMID:21130996] http://dx.doi.org/10.1016/j.jbiomech.2010.11.016

54. Formica D, Charles SK, Zollo L, Guglielmelli E, Hogan N, Krebs HI. The passive stiffness of the wrist and forearm. J Neurophysiol. 2012;108(4):1158-66. [PMID:22649208] http://dx.doi.org/10.1152/jn.01014.2011

55. Rijnveld N, Krebs HI. Passive wrist joint impedance in flexion-extension and abduction-adduction. Proceedings of the 10th IEEE International Conference on Rehabilitation Robotics; 2007 Jun 13-15; Noordwijk, the Netherlands. p. 43-47. http://dx.doi.org/10.1109/ICORR.2007.4428404

56. Palazzolo JJ, Ferraro M, Krebs HI, Lynch D, Volpe BT, Hogan N. Stochastic estimation of arm mechanical impedance during robotic stroke rehabilitation. IEEE Trans Neural Syst Rehabil Eng. 2007;15(1):94-103.

[PMID:17436881]

Submitted for publication October 31, 2011. Accepted in revised form August 21, 2012.

This article and any supplementary material should be cited as follows:

Roy A, Forrester LW, Macko RF, Krebs HI. Changes in passive ankle stiffness and its effects on gait function in people with chronic stroke. J Rehabil Res Dev. 2013; 50(4):555-72.

http://dx.doi.org/10.1682/JRRD.2011.10.0206

ResearcherID/ORCID: Anindo Roy, PhD: E-4312-2012

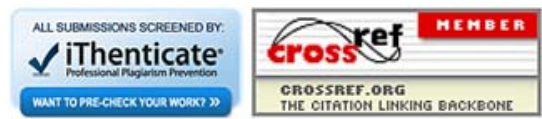


